\title{
Cost and Profit Optimization and Mathematical Modeling Solutions to Stochastic Processes in Inventory System
}

\author{
Dr. Vivek Kumar Sharma \\ Professor \\ Jagannath University, Jaipur \\ Dr. Rudresh Pandey \\ Associate Professor \\ Jagannath International Management School (JIMS), Kalkaji, New Delhi. \\ Shradha Goyal \\ Research Scholar (Ph.D) \\ Jagannath University \\ Jaipur
}

\begin{abstract}
For an industry, management of the inventory of finished goods or goods to be sold is very crucial. One of the important aspects of financial analysis is the inventory turnovers for ecommerce companies. This forms a major base for decisions of the firm's management. By traditional theory of inventory, it is believes that high turn over results in stock outs and low turn over leaves high unused and outdated stock to be maintained. Thus, an effective inventory management should focus on maintaining a balance between different levels of inventory. This paper looks into the development of an analytical model for optimization of turnover ratio under well managed inventory keeping in mind the upcoming production industry. The model in this paper aims at optimizing average annual total cost and the optimum quantity of inventory, to attain maximum turnover ratio depending on various cost of involved in inventory maintenance like holding cost, procurement cost, operating cost etc. Secondly, this paper discusses about formulation of average annual total cost function under Inventory Management Policy which can be used for effective supply chain. The results of the models are justified using comparison of initial and final values in a hypothetical problem.
\end{abstract}

Key words:- inventory, optimization of turnover ratio, analytical model, average annual total cost

\section{INTRODUCTION \& LITERATURE REVIEW}

Inventory is a foremost part of the balance sheet, its management and optimization can make huge financial differences for any business. A major mast of success for a manufacturing unit is the optimization of the inventory. A major objective of inventory management is to keep the adequate levels of inventory to serve the customer needs with minimum cost. (Brigham \& Ehrhard, 2005)

(Waters 2008), has defined inventory as various items that are in stock of the organization for future use. Manufacturing units face a challenge to lower the cost of supply chain and reduce the time of throughput. As Inventory is a major cost in the production process therefore it under the constant pressure. Reducing inventory levels is a direct reduction of cost. To increase product choice, give more reliable dates and improved customer service and quality are also major objectives. (Umbel et.al 2008). If Inventory is reduced without proper planning it will affect adversely on the overall performance of the business. Inventory management is a complex subject and is certainly more than just forecasting and replacement of stock. Inventory management is all about optimization of services to customer and maximization of profits. Inventory management involves modeling which is done with an 
objective to understand lead times, quantities to be shipped or for stockholdings. EOQ (economic order quantity) needs to be established and other aspects of supply chain should be looked into. (Andrew Blatherwick, 2006)

(Chambers, Lacey, 2011) Gives a study that says that foremost purpose of maintaining inventory is to keep it available to consumer always. Therefore, optimizing the levels of inventory mentioned eventually becomes important for further optimization of cost benefits related to it. Size of the product in inventory also affects the cost like storage, damage, security etc. Hence the profit ratio varies accordingly (Shim, Siegel, 2007). In continuation to this various cost factors depend on effectively managed inventory, are like, rate of interest, sales, production, reliable supply chain, funds for inventory etc. the rate of Holding inventory decreases and rate of interest on cost increases(Shim, Siegel, 2008). Just in Time technique of manufacturing, Intra company exchange of material, apply technical and suitable inventory control systems, better purchasing practices from vendor, raw material to be bought according to lot size, setting up of review system of inventory are some of the recommendations for inventory management in an organization(McComas, 1995). The main Challenge for Manages in an Organization is to maintain inventory stock along with reduction in its holding cost and up gradation of turnover ratio (Brigham, Daves, 2004). Considering EOQ inventory techniques is recommended for optimal size of order to be placed within minimum ordering cost and holding cost. These costs are dependent on amount ordered as; large order place at one time will reduce the no. of orders required and hence reduce the ordering cost, but will require maintenance of the extra inventory and hence increase the holding cost. Whereas, small orders will reduce holding cost but will require frequent ordering and hence will increase ordering cost. Therefore, few assumptions are recommended for classical EOQ technique, like, constant demand and depletion of stock, with no quantity discounts. Hence, this explains the swapping between the inventory size, set-up cost and the holding cost (Yan and Kulkami, 2008).

Along with EOQ, there is another method that can help manage inventory better. This is the method of safety stock and Reorder point (ROP), where the time and size of order is pre fixed for further process (Fangruo Chen, 1998)

If the demand and Lead time are constant and known,

ROP $=($ Lead time $) X$ (Daily requirement).

And, ROP $($ with safety stock $)=\{($ Lead time $) X($ Daily requirement $)\}+$ Safety stock. $($ Gonzales, 2010).

(Baldenius and Reichelstein, 2000) established that the left over income act based on historical cost accounting gives management with additional options to make optimizing decisions for keeping inventory and production updated. At times, when there are uncertain fluctuations in demand, the best rule followed is to take the lower out of cost or market demand, so that the inventory stocks do not become meaningless.

Lai (2005 and 2006) provides experiential proof that the market does not accept the firms with poor inventory performance and fail to explain the firm value through its inventory. It suggests that in today's signal influenced world, inventory behave as a signal to firm's outlook. At last, the model was developed assuming a firm as Huge, Allied body, without intermediates between company and consumer.

Ozer (2009) suggests 4 Principles followed by managers for effective inventory management:

(a) Knowledge about the optimum use of resources

(b) Keep increasing and updating with this knowledge

(c) They should consider inventory operations separately.

(d) The decision made for inventory management should be well explained to the users.

According to Wang et al. (2013) the conventional inventory models works to characterize replacement policies in order to optimize the net profit or net cost over a designed sphere. They provide the viewpoint of inventory problems as a major part of financial risk managing. The aim is to formulate inventory as a constant stochastic optimal management problem with permanent and relative operation costs restricted by continuous value-at-risk. The results show the relationship between cost of raw material, lvel of inventory and restriction od risk of value.

Control of Inventory is considered as a function of management comprising of forecasting, determining targets and issuing instructions. Leeuw et al (2011) has stated that inventory is a core issue of operations management, 
Inventory is a major cost of entire supply chain. The propose of inventory management is to determine the levels of inventory with various variables like lead times of supply and delivery under the uncertainty of supply and delivery and demand. (Rumyyantsev and Netessine, 2007). This may not be true in all industry as Debelaar et al (2011), has stated this for fashion supply chains. Various models of inventory ignore complications of supply chains due to competition in market and decision making at various levels and business cycles.

Despite the global acceptance of just- in -time (JIT) and logistics concept in academia and industries from the 1990s to date, a lot of empirical studies have not been able to achieved any meaningful decrease in finish goods inventory levels in many different industries, which work in progress inventory and raw material stocks have consistently decreased over time(Leeuw et al, (2011),

\section{OBJECTIVE OF THE RESEARCH}

A major functional area of management for business is managing the inventory of raw material or finished goods. With emergence of widely spread industry traditional inventory management has taken a important role for the purpose of management of stock which become the basis for profitability and value creation. As in any production system which is concerned with the management of physical resources for the production of an item or provision of a service, Ecommerce also has to manage its inventory for managing its value chain and meeting the demands of customer. Competitive advantage of ecommerce companies rest on management of their value chain. Success of an ecommerce company will depend on the management of its stock and inventory as most of the ecommerce companies' work on thin margins with large volumes. Objective of this research is to create analytical model for cost optimization and mathematical modeling solutions to stochastic processes in inventory system with reference to ecommerce industry. The model aims at optimizing average annual total cost and the optimum quantity of inventory to attain maximum turnover ratio depending on various cost of inventory maintenance like holding cost, procurement cost and operating cost etc. this paper discusses about formulation of average annual total cost function under Inventory Management Policy which can be used for a ecommerce supply chain.

\section{Research Questions}

1. Study the effect of effective inventory management policy on optimization of turnover ratio.

2. Review of inventory model to study the effect of alternating pricing policies on finite rate of production.

\section{Research outcomes}

1) The model 1 is based on designing effective management policy to optimize turn over ratio, based on various assumptions of no Shortages and zero lead time, Also assuming Instant replenishment and Constant and predictable annual demand, money value and future cost. Keeping these assumptions in view and using a basic concept of Local maximization of differentiation and higher order differebtial equations, the following model was developed for effective optimum turn over ratio,

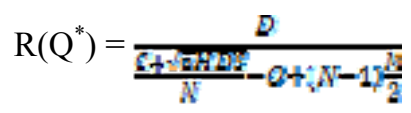

And at an Annual Average Total cost of,

$$
A A T C=\frac{C+\sqrt{2 \pi D S}}{N}+0+(N-1) \frac{M}{2}
$$

With the help of sensitivity analysis of the above model it is hence concluded that increase in demand and increase in life years of assets (table 1) and increase in demand but fixed life years of assets (table 2). In both the mentioned situations the AATC, $Q^{*}, \mathbf{R}\left(\mathbf{Q}^{*}\right)$ increases under inventory management policy. This 
contradicts the traditional approach of decrease in inventory turn over ratio when total cost increases because of increase in contract quantity. The method discussed here gives better and profitable results.

2)

The Model 2 is

constructed with the objective of analyzing the effect of optional pricing policy on limited production rate using Just - In - time inventory model. considering certain assumptions like known demand and dependency of demand on selling price, no lead time, fixed rate of production $(\lambda)$ and set up cost per unit, no backorders allowed. Keeping these assumptions in view a profit function ZQ is first analyzed, as

$$
\mathrm{ZQ}=\mathrm{DP}-\mathrm{CQ}-\sum_{i=1}^{k}\left[N_{t}+P_{t} Q O_{i} E_{i}\left(1+\frac{D}{A}\right)+L_{i} S_{t}+M_{i} \frac{D}{Q}\right]
$$

This profit function ZQ is dependent on demand, price, unit cost, total daily cost. The objective further, is to determine the optimized size of lot $(\mathrm{Q})$ for which the profit function gives the maximum value. Hence, derivating the profit function $Z Q$, we can find the optimized value of $Q$, given by the critical points, keeping in mind, satisfaction of certain conditions, side by side. Further these values of $\mathrm{Q}$ and $\mathrm{ZQ}$ were tested on the basis of 2 different pricing policies based on Demand $(\mathrm{D}=\mathrm{f} \theta \mathrm{CQ})$ and price $(\mathrm{P}=\mathscr{Q} C \mathrm{Q})$ i.e Policy 1:- When Demand D and Price P are constants.

Policy 2: When Demand D and Price P are variables.

The above stated policies are applied to a linear cost function representing linear quantity discounts.

With consideration of the above stated assumption, pricing policies and cost function the following conclusions were made.

Policy I

(a) For constant $\mathrm{C}_{0}$ the incease in rate of production $\lambda$, results in increased order Quantity $\mathrm{Q}^{*}$ and profit $\mathrm{Z}\left(\mathrm{Q}^{*}\right)$.

(b) For fixed rate of production $\lambda$, decrease in $\mathrm{C}_{0}$, gives constant order quantity $\mathrm{Q}^{*}$ and increase in profit $\mathrm{Z}\left(\mathrm{Q}^{*}\right)$.

(c) If, Rate of production $\lambda$ decreases and $\mathrm{C}_{0}$ increases, then decrease is observed in both profit $\mathrm{Z}\left(\mathrm{Q}^{*}\right)$ and optimal order quantity $Q^{*}$.

(d) For increase in $\lambda$ and decrease in $\mathrm{C}_{0}$, there is an increase in both profit $\mathrm{Z}\left(\mathrm{Q}^{*}\right)$ and optimal order quantity $Q^{*}$.

Policy II

(a) For constant $\mathrm{C}_{0}$ and increase in $\theta$, there is decrease in order quantity $Q \&$ and increase in profit $Z_{\theta}^{*}$.

(b) For constant $\theta$ and decrease in $\mathrm{C}_{0}$, there is increase in order quantity $Q \%$ and decrease in profit $Z_{\%}$.

(c) For increase in $\theta$ and decrease in $\mathrm{C}_{0}$, there is increase in both order quantity $Q$ and profit $Z$.

(d) For decrease in $\theta$ and increase in $\mathrm{C}_{0}$, there is decrease in both order quantity $Q 8$ and profit $Z$ :

Research Limitations 
This research aims to create models for inventory management on hypothetical values and by using online softwares for sensitivity analysis. This is a major limitation of this research as this model needs to be verified and tested in real world problems. Further scope of this research is to test the models and implement them.

\section{REFERENCES}

[1] Baldenius, T., Reichelstein, S. (2000). Incentives for Efficient Inventory Management: The Role of Historical cost, Available at: http://dx.doi.org/10.2139/ssrn.218328/

[2] Blatherwick, A. (2006),"The supply chain balancing act - stock and service at a profit", Logistics Information Management, Vol. 9 Iss: 6 pp. $24-26$

[3] Brigham, E. F., Daves, P. R. (2004). Intermediate Financial Management, Eight Edition, Ohio: Thomson.

[4] Brigham, F., Ehrhardt, M. (2005) Financial management theory and practice. 11th ed. Mason, OH: Thomson/South-Western.

[5] Chambers, D., Lacey, N. (2011). Modern Corporate Finance, Sixth Edition, Michigan: Hayden McNeil Publishing.

[6] Chen, F. (1998), „Echelon Reorder Points, Instalation Reorder Points, and the Value of Centralized Demand Information“, Management Science, Vol. 44, No. 12.

[7] Dubelaar, C., Chow, G., Larson, P. (2011), "Relationships between inventory, sales and service in a retail chain store operation", Management, Vol. 31 No. 2, pp. 96-108.

[8] Lai, R. (2006). Inventory Signals, Harvard NOM Research Paper No. 06-09, Available at: http://ssrn.com./abstract=723381/

[9] McComas, C. (1995). Controlling Purchasing and Inventory to Reduce Waste, Pollution Prevention Review, 5.

[10] Ozer, O. (2009). Inventory Management: Information, Coordination and Rationality, Available at: http://ssrn.com/abstract=1351628/

[11] Rumyantsev, S. and Netessine, S. (2007), "What can be learned from classical inventory models? A cross-industry exploratory investigation", Manufacturing \& Service Operations Management, Vol. 9 No. 4, pp. 409-29.

[12] Shim, J. K., Siegel, J. G. (2008). Financial Management, New York: McGraw Hill.

[13] Umble, E., Haft, R., Umble, M., (2008) Enterprise Resource Planning: Implementing Procedure and Critical Success Factors. European Journal of Operational Research Vol.146, Issue 2 [online] available from http://www.sciencedirect.com

[14] Wales: McGraw-Hillllrwin. Leeuw, S., Holweg, M., Williams, G.(2011),"The impact of decentralised control on firm-level inventory: Evidence from the automotive industry", International Journal of Physical Distribution \&Logistics Management, Vol. 41 Iss: 5 pp. 435 456.

[15] Wang, S., Yin, K., Mak, K. (2013), „Optimal Inventory Policy with Fixed and Proportional Transaction Costs Under a Risk Constraint“, Mathematical and Computer Modelling, Vol. 58, No. 9-10.

[16] Water, D. (2008) Inventory Control and Management. 2 edn. John Wiley \& Sons.

[17] Yan, K., Kulkami, V. (2008), „Optimal Inventory Policies Under Stochastic Production and DemandRates“, Stochastic Models, No. 24.

\section{Appendix}

\section{Model 1}

\section{EFFECTIVE INVENTORY MANAGEMENT POLICY TO OPTIMIZE TURNOVER RATIO}

\section{$\underline{\text { Assumptions and Notations }}$}

The model is developed under the following assumptions and notations:-

C: cost at zero time

H: holding cost of inventory

Q: lot size/production run

D: total stock (produced, purchased or supplied) throughout the time.

S: fixed initial cost/production run on procurement cost

O: Aggregate annual operating cost and relative maintenance cost.

M: annual increase in maintenance cost

$\mathrm{N}$ : life years of assets. 


\section{Assumptions:-}

3) No shortages

4) Zero lead time

5) Instant replenishment

6) Constant and predictable annual demand

7) Constant money value with respect to time

8) Predictable feature cost at the time of asset purchase.

9) Similar cost of replenishment

\section{Problem Statement and Algorithm}

The objective of the paper is to formulate a model to determine optimum turnover ratio under Inventory management Policy.

Neglecting the interest factor, the Average of Annual Total Cost(AATC) for an asset with respect to increasing maintenance cost can be stated as:

$$
A A T C=\stackrel{C+(T C)}{N} \text { O। }(N \quad 1){ }_{2}^{M}
$$

Where, $\mathrm{TC}=$ Total annual cost of stock $=\frac{E Q}{\mathrm{E}}+\frac{P Q}{Q}$

That is, $\mathrm{TC}=\frac{H \Omega^{2}+2 \pi \Omega}{2 E Q}$

Thus the Turnover ratio for the inventory model when AATC of an Asset, considering increasing maintenance cost, is :-

$\mathrm{R}(\mathrm{Q})=\frac{Q}{A A T C}$

$\Rightarrow \mathrm{R}(\mathrm{Q})=\frac{D}{\frac{[\mathrm{HLD}}{N}-O+(N-1) \frac{4}{2}}$

$\Rightarrow R(Q)=\frac{2 N D Q}{2 C Q+2 R Q Q^{2}+2 D S+2 N Q Q+(N-1) M Q Q}$

First order derivative of (4) w.r.t $\mathrm{Q}$ and equating to 0 .

We get,

$\frac{\partial R(Q)}{\partial Q}=\frac{4 D^{2} S N-2 H Q^{2} N D}{2 C Q+H Q^{2}+2 D S+2 N Q Q+(N-1) M N Q^{2}}=0$

Simplifying the above equation for value(s) of $Q$, we get, $Q^{\circ}=\sqrt{\frac{P D S}{H}}$

Now according to the maximization algorithm, for turnover ratio to be maximum, the sufficient condition $\frac{g^{2} B(Q)}{g Q 2}<0$, have to be satisfied. 
Therefore for the above sufficient condition, it is stated that,

$2 C Q+H Q^{2}+2 D S+2 N Q Q+(N-1) M N Q+H Q+H Q^{2}-2 D S+2 C+2 H Q+2 N Q+(N-1) M N$

(6)

Substituting the value of $Q^{\text {th }}$ from (5) in (2), we get,

$\mathrm{TC}=\sqrt{2 R 2 S}$

Also substituting TC in (1), we get

$A A T C=\frac{C+\sqrt{2 E D S}}{x}+0+(A-1) \frac{A}{2}$

And hence the turnover ratio, is

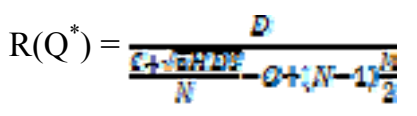

\section{Hypothetical Problem:-}

Initially let us consider, the given data as for a month.

$\mathrm{H}=$ Rs.5/Production.

$\mathrm{O}=$ Rs.250 (Aggregate annual operating cost and relative maintenance cost)

$\mathrm{C}=$ Rs. 1000

$\mathrm{S}=$ Rs. 25

$\mathrm{M}=$ Rs. 10

\section{Table 1}

\begin{tabular}{|l|l|l|l|l|}
\hline $\mathbf{D}$ & $\mathbf{N}$ & $\mathbf{A A T C}$ & $\mathbf{Q}^{*}$ & $\mathbf{R}\left(\mathbf{Q}^{*}\right)$ \\
\hline 5500 & 20 & 443.62 & 1172.60 & 12.36 \\
\hline 6500 & 25 & 460.94 & 1274.74 & 14.10 \\
\hline 7500 & 30 & 473.97 & 1369.30 & 15.82 \\
\hline 8500 & 35 & 490.22 & 1457.73 & 17.33 \\
\hline
\end{tabular}


Table 2

\begin{tabular}{|l|l|l|l|l|}
\hline $\mathbf{D}$ & $\mathbf{N}$ & AATC & $\mathbf{Q}^{*}$ & $\mathbf{R}\left(\mathbf{Q}^{*}\right)$ \\
\hline 5500 & 30 & 467.42 & 1172.60 & 11.76 \\
\hline 6500 & 30 & 470.82 & 1274.74 & 13.80 \\
\hline 7500 & 30 & 473.97 & 1369.30 & 15.22 \\
\hline 8500 & 30 & 476.92 & 1457.73 & 17.82 \\
\hline
\end{tabular}

\section{$\underline{\text { Conclusion }}$}

Considering increase in demand and increase in life years of assets (table 1) and increase in demand but fixed life years of assets (table 2). In both the mentioned situations the AATC, $\mathbf{Q}^{*}, \mathbf{R}\left(\mathbf{Q}^{*}\right)$ increases under inventory management policy. This contradicts the traditional approach of decrease in inventory turn over ratio when total cost increases because of increase in contract quantity. The method discussed here gives better and profitable results.

Model 2

\section{EFFECT OF OPTIONAL PRICING POLICY ON LIMITED PRODUCTION RATE USING WITH REFERENCE TO JIT INVENTORY MODEL}

\section{NOTATIONS AND ASSUMPTIONS:}

The model is developed under the following notations:-

D: Demand per day

P: Selling price per unit

$\lambda:$ rate of production

$\mathrm{C}_{\mathrm{s}}$ : cost of set up/unit

$\mathrm{T}$ : total time of one round of production.

$\mathrm{N}_{\mathrm{i}}$ : queue size of lots, at i operation

$P_{i}$ : lot size in operation, at $i$ operation

Q: Total number of lots

$\mathrm{O}_{\mathrm{i}}$ : Value of the part, at i operation 
R: daily rate of Holding cost

Mi: set up material cost at $\mathrm{i}$ operation

$\mathrm{L}_{\mathrm{i}}$ : rate of labor for set up, at $\mathrm{i}$ operation

$\mathrm{Si}$ : total Set up time, at i operation

$\mathrm{k}$ : Total operations

\section{Assumptions:}

1. Demand can be determined. The rate of demand $\mathrm{D}$ is dependent on the selling price per unit $\mathrm{P}$ for demand at any instant.

2. No Lead time. Single delivery of order is assumed.

3. The rate of production $\lambda$ is constant and limited, and is strictly higher than the rate of demand

$(\lambda>\mathrm{D})$.

4. Unit cost of set up $\mathrm{C}_{\mathrm{s}}=\mathrm{L}_{\mathrm{i}} \mathrm{S}_{\mathrm{i}}+\mathrm{M}_{\mathrm{i}}$ is constant.

5. Not to allow Backorders.

\section{Problem Statement}

The problem here considers inventory system in a factory ware house, where the stock arrives after being produced in different lots in the factory. The main focus of the problem is on selling of single product, its storage and production. The constant and finite rate of production of the product in the factory is $\lambda$. The available stocks are piled in the warehouse and are used to fulfill the consumer demand constantly which is assumed to be determined at the rate of $D$. Because of the assumption $\lambda>\mathrm{D}$, it is ensured that the consumer demand is satisfied, provided the production process is continuous. Therefore, $(\lambda-D)$ units are added to the inventory per unit time. Since the rate of production is assumed to be finite, the first shift of production goes on for a time period of $t_{1}$ units, and then it stops till time period of $t_{2}$ units, during which the stocks in the ware house are used to fulfill the continuous consumer demand, till the stock gets used up. This total time of $t_{1}+t_{2}$ is the total cycle time (T) of the process, i.e. $T$ $=t_{1}+t_{2}$. Next Assumption we have made is that no shortages should be there, therefore, the production has to start immediately after time $\mathrm{T}$ and the procedure $\mathrm{T}=\mathrm{t}_{1}+\mathrm{t}_{2}$ continues continuously, as our model assumptions are infinite in nature.

The units produces reach the consumers at the rate of Rs. P / unit time. We need to introspect what should be the size $\mathrm{Q}$ of the lot to be kept ready for sale, in order to avoid stock outs and earn maximum profit in the system.

\section{$\underline{\text { Algorithm }}$}

At any time say, $t$, let $Q(t)$ be the lot size. We considers two different time intervals $\left(0, t_{1}\right)$ and $\left(t_{1}, T\right)$ and, the stock level increases at the rate of $(\lambda-D)$ units/unit time and then falls at the rate of $\mathrm{D}$ units/unit time, respectively in the time intervals.

$$
\begin{aligned}
\frac{d Q(t)}{d t} & =\lambda-D, 0 t_{1} t t_{1} t_{1} \\
& =-D, t, s \pm t
\end{aligned}
$$


Also see that, $\mathrm{Q}(0)=\mathrm{Q}(\mathrm{T})=0$

The solution of Equation (1) can be stated as

$\mathrm{Q}_{1}(\mathrm{t})=\lambda-D \mathrm{t}$,

$0 s_{1}$

$\mathrm{Q}_{2}(\mathrm{t})=\mathrm{T}-\mathrm{tD}$, $t_{1} \leq t$

But, $\mathrm{Q}_{1}\left(\mathrm{t}_{1}\right)=\mathrm{Q}_{2}\left(\mathrm{t}_{2}\right)$

$\Rightarrow$

$$
\frac{D Y}{A}=\frac{Q}{A} \quad Q=D T
$$

$t_{t}=$

Hence, we can also conclude that at i operation, the cost of holding, per day, per unit time is:-

$$
\mathrm{C}_{1}=\mathrm{CQ}\left(1+\frac{2}{\mathrm{~g}}\right), \quad \text { where } \mathrm{CQ}=\text { per unit cost } / \text { unit time }
$$

Also, $\quad C Q=\Sigma_{i=1}^{k} N_{t}+P_{i} Q Q_{i} E^{*}$

$\Rightarrow$

holding cost/unit time for all $\mathrm{k}$ operations will be:-

the daily

$$
\mathrm{C}_{1}=\left[\Sigma_{t=1}^{k} N_{t}+P_{t} \dot{\varepsilon}_{t} U_{t}\left(1+\frac{n}{\lambda}\right)\right]
$$

Number of lots decides the daily set up requirement and hence the daily cost of set up. Individual set up cost is summation of cost of used material and labor cost.

At $\mathrm{i}$ operation, the daily set up cost, can be expressed as:-

$$
\mathrm{C}_{\mathrm{s}} \text { at } \mathrm{i} \text { operation }=\mathrm{L}_{\mathrm{i}} \mathrm{S}_{\mathrm{i}}+\mathrm{M}_{\mathrm{i}} \frac{D}{Q}
$$

Therefore, using this model, for total k operations, the cost of set up per unit time is

$$
\mathrm{C}_{\mathrm{s}}=\sum_{i=1}^{k} F_{i} \mathrm{~S}_{\mathrm{i}}+\mathrm{M}_{\mathrm{i}} \frac{D}{Q}
$$

$\Rightarrow$

cost/day/unit time is $\mathrm{C}=\mathrm{C}_{1}+\mathrm{C}_{\mathrm{s}}$

$$
\text { i.e } \mathrm{C}=\sum_{i}^{k+1}\left[N_{t}+E_{t} Q Q_{t} R\left(1+\frac{Q}{a}\right)+L_{i} S_{i}+M_{t} \frac{Q}{Q}\right]
$$

if Rs. P is set as selling price of one unit/unit time, then profit earned by the system can be expressed as

Profit $=($ Total Revenue $)-($ Total cost $/$ day $)$

Where, Total Revenue $=$ DP - CQ

Substituting (8) in (7), we get profit as

$$
\mathrm{ZQ}=\mathrm{DP}-\mathrm{CQ}-\sum_{i=1}^{k}\left[N_{t}+P_{t} Q O_{t} E\left(1+\frac{D}{A}\right)+E_{t} S_{t}+M_{t} \frac{D}{Q}\right]
$$


It is noticed here that profit function ZQ is dependent on demand, price, unit cost, total daily cost.

The model here will focus on determining $\mathrm{Q}$ is the optimum Lot size for which the profit ZQ is optimum.

Hence from (9), $\frac{g z}{g Q}=Q$; will help us determine the optimal value of $Q$ (also written as $Q^{*}$ ) and hence determine the maximum profit, once the sufficient conditions are satisfied.

We study the effect of alternative pricing policies on the above stated maximization problem. The different pricing policies (based on price $\mathrm{P}$ and demand $\mathrm{D}$ ) are as follows:-

\section{Policy 1: When Demand D and Price P are constants}

Here, the Demand is assumed to be known and constant. Also per unit Selling Price P is constant and independent of Cost per unit.

\section{Policy 2: When Demand D and Price $P$ are variables}

Here, the Demand is assumed to be known and variable. Per unit selling price $\mathrm{P}$ is directly proportional to order Quantity $\mathrm{Q}$ and is related as:

$$
P=\mathbb{P C Q} \text {, where } 9 \geqslant 1 \text { is constant }
$$

The demand $\mathrm{D}$ is dependent on Price $\mathrm{P}$ and further $\mathrm{P}$ is dependent on type of cost function (CQ).

This is represented as demand function, $\mathrm{D}=\mathrm{fP}$, where $\mathrm{P}, \mathrm{D}>0$

The demand function (11) is monotonically non - increasing, continuous, real and single valued function of Q.

Hence (10) and (11) shows demand function for fixed mark - up of prices,

$$
\mathrm{D}=\mathrm{f} \theta \mathrm{CQ}
$$

Pricing policies 1 and 2 stated above, different nature of discounts in Quantity are studied, under 2 different types of costs functions.

\section{Introduction to Cost Functions Quantity discounts are Linear}

Consider a Unit Cost function C (Q), as

$$
\mathrm{C}(\mathrm{Q})=\mathrm{C}_{0}-\alpha \mathrm{Q}
$$

Where $\mathrm{C}_{0}>0, \alpha \geq 0_{\mathrm{r}}\left(\mathrm{C}_{0}>\boldsymbol{\alpha}\right)$ are constants and $\mathrm{C}(\mathrm{Q})>0 \forall \mathrm{Q}$

Initially, keeping an optimum value fixed, the bigger size of the purchased order decreases the cost linearly. This is called the quantity discounts $(\boldsymbol{F})$. The cost becomes constant when no quantity discounts are there. i.e when $a=0$, then $\mathrm{C}(\mathrm{Q})=\mathrm{C}_{0}=$ Constant. This is, when no discounts are considered, the cost remains constant.

\section{Case (II) : Hyperbolic Quantity Discount :}

In this consider the per unit cost function CQ as:-

$$
\begin{aligned}
& C Q=C_{0} \quad 0 \leq Q \leq Q_{0} \\
& =b+\frac{d}{Q}\left(Q_{0} \leq Q<\infty\right)
\end{aligned}
$$

Where $\quad C_{0}>0, b>0$ and $d \geq 0$ are constant, $C Q>0 \forall Q$ 
As in the case of linear quantity discounts, here also cost function in (14) is considered with maximum cost initially. But here, we consider fixed as well as variable cost, so that with the increase in total demand there is variation in unit cost CQ. Also in (14), observe that as $Q \rightarrow \infty, C Q \rightarrow b$. Hence, $C Q=b$, is dual representation of no discounts at constant cost and secondly as $Q \rightarrow \infty$, (14) given an asymptote for the curve representing cost. Cost function I \& II can be graphically represented.

In the eqn of cost function (14) we consider $Q=Q_{0}$.

$$
\begin{aligned}
& \Rightarrow \quad C_{0}=b+\frac{d}{Q_{0}} \\
& \Rightarrow \quad Q_{0}=\frac{d}{C_{0}-b}
\end{aligned}
$$

From the fig. (1) we can observe that cost curves intersect $Q=Q_{1}$ and $Q=Q_{2}$, where

$$
\begin{aligned}
& Q_{1}=\frac{C_{0}-b}{2 \alpha}+\frac{C_{0}-b^{2}}{2 \alpha}-\frac{d^{1 / 2}}{\alpha} \\
& Q_{2}=\frac{C_{0}-b}{2 \alpha}+\frac{C_{0}+b^{2}}{2 \alpha}+\frac{d^{1 / 2}}{\alpha}
\end{aligned}
$$

Where values of constants $C_{0}, b, a, d$ are dependent as $Q_{0}>Q_{1}>0$.

The values of $Q_{1}$ and $Q_{2}$ set the lower \& upper limits respectively for the lot size $Q$ \& it cost functions.

\section{Working Algorithm for Policy I considering the Linear Cost Function}

Here we consider Demand D and Price $P$ are constants,

Considering equation (9) and (13) we get profit function $Z(Q)$ as,

$\mathrm{Z}(\mathrm{Q})=\mathrm{DP}-\mathrm{C}_{0}+\alpha \mathrm{Q}-\sum_{i=1}^{k} N_{i}+E_{i} Q Q_{i} E^{2}\left(1+\frac{D}{d}\right)+\sum_{i=1}^{k}\left(L_{t} g_{t}+M_{i} \frac{D}{Q}\right)$

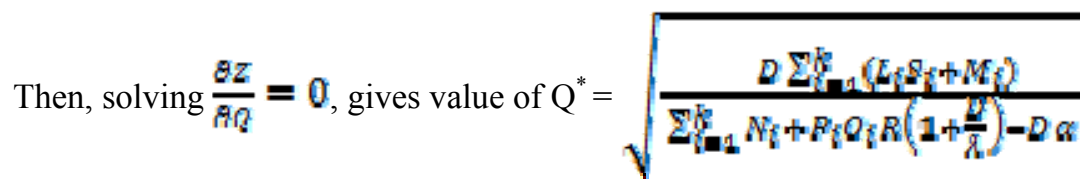

Substituting $\mathrm{Q}=\mathrm{Q}^{*}$ from (15) in (14) to get the $\mathrm{Z}^{*}$

\section{Special Cases:-}

(a)

when $\alpha=0$,

$$
\mathrm{C}(\mathrm{Q})=\mathrm{C}_{0}=\text { constant }
$$




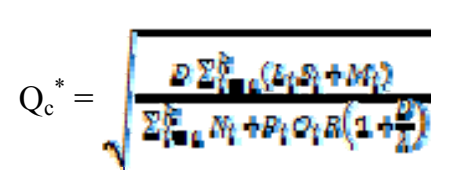

And $Z_{c}^{*}=\mathrm{DF}-Q_{0}-2 \sqrt{\sum_{i=1}^{k} N_{i}+E_{i} Q_{i} R^{2}\left(1+\frac{D}{d}\right)+\sum_{i-1}^{k}\left(L_{t} g_{t}+M_{i} D\right)}$

(b)

equation (18) and (19) gives,

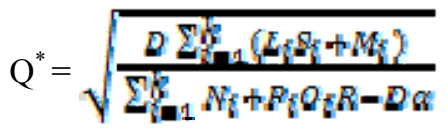

And

$\mathrm{Q}_{\mathrm{c}}^{*}=\sqrt{\frac{\left.D \sum_{i}^{k} \mathcal{L}_{i} S_{i}+M_{i}\right)}{\sum_{i=1}^{k} N_{i}+P_{i} O_{i} R}}$

\section{Case (b) : Hyperbolic Cost Function}

Here, using equation (9) \& (14), where cost in considered; variable by:-

$$
\begin{aligned}
& C Q=b+\frac{d}{Q},\left(Q_{0} \leq Q<\infty\right) \\
& Z Q=D P-b-\frac{d}{Q} \sum_{j=1}^{k} N_{i}+P_{i} Q O_{i} R\left(1+\frac{D}{\lambda}\right)+\sum_{j=1}^{k} L_{i} S_{i}+M i \frac{D}{Q}
\end{aligned}
$$

Hence $\frac{\partial Z}{\partial Q}=0$ gives, $Q^{*}$ and hence using (23) we get $Z^{*}$

$$
Q^{*}\left[\frac{D d+\sum_{j=1}^{k} L_{i} S_{i}+M_{i}}{\sum_{j=1}^{k} N_{i}+P_{i} O_{i} R\left(1+\frac{D}{\lambda}\right)}\right]^{1 / 2} Q^{*}
$$

\section{Case of Constant Cost:}

In (23) and (24),

$$
\text { If } 0 \leq Q \leq Q_{0}, C Q=C_{0}=\text { CONSTANT }
$$

Then we can see that values of $Q_{c}{ }^{*}$ and $Z_{c}{ }^{*}$ are same as that in (19) \& (20) stated before.

If $Q_{0} \leq Q<\infty$, then this is considered again for Constant cost with no discounts for quantity. 
Hence, we have

$$
Q_{c}^{*}=\left[\frac{D \sum_{i=1}^{k} L_{i} S_{i}+M_{i}}{\sum_{i=1}^{k} N_{i}+P_{i} O_{i} R\left(1+\frac{D}{\lambda}\right)}\right]^{1 / 2}
$$

and

$$
Z_{0}^{*}=D P-b-2\left[\sum_{i=1}^{k} N_{i}+P_{i} O_{i} R\left(1+\frac{D}{\lambda}\right)\right]\left[D \sum_{i=1}^{k} L_{i} S_{i}+M_{i} D\right]^{1 / 2}
$$

\section{Limiting Case :}

Taking a special case of unlimited rate of production ie $(\lambda \rightarrow \infty)$, we get using (24) \& (25).

$$
Q^{*}=\left[\frac{D d \sum_{i=1}^{k} L_{i} S_{i}+M_{i}}{\sum_{i=1}^{k} N_{i}+P_{i} O_{i} R}\right]^{1 / 2}
$$

And

$$
Q_{c}^{*}=\left[\frac{D \sum_{i=1}^{k} L_{i} S_{i}+M_{i}}{\sum_{i=1}^{k} N_{i}+P_{i} O_{i} R}\right]_{Q_{c}^{*}}^{1 / 2}
$$

\section{Working Algorithm for Policy II considering the Linear Cost Function}

Here we assume that

(i)

(iii) discounts

demand $\mathrm{D}$ is variable mark up price $\mathrm{P}$ is fixed cost functions allow quantity

Then Profit function $Z(Q)$ can be calculated from equation (9) and equation (12)

$$
\mathrm{Z}(\mathrm{Q})=(\theta-1)(\mathbf{C Q}) \mathrm{f} \theta \mathrm{CQ}-\sum_{i=1}^{N}\left[N_{i}+P_{i} Q O_{i} R\left(1+\frac{D}{a}\right)+\left(L_{i} S_{i}+M_{i}\right) \frac{\varphi 00 \mathrm{Q}}{Q}\right]
$$

Let us consider, the demand law as $\mathrm{D}=\boldsymbol{K} \boldsymbol{F}^{\boldsymbol{\eta}}$, 
where $\eta$ is the elasticity of demand $\sigma(0, \infty)$

therefore, (29) and (30) gives,

$$
\begin{aligned}
& \mathrm{Z}(\mathrm{Q})= \\
& K \theta^{-\eta}(\theta-1)(C Q)^{n+1}- \\
& {\left[\sum_{i=1}^{k}\left(N_{i}+P_{i}\right) Q O_{i} R-\right.} \\
& \left.\left.\frac{1}{\lambda} \sum_{i=1}^{k}\left(N_{i}+P_{i}\right) Q O_{i} R K \theta^{-\eta}(C Q)^{-\eta}+\sum_{i=1}^{k} \frac{\left(L_{l} \Omega_{l}+M_{i}\right) K(C Q)^{-\eta}}{Q \theta^{\eta}}\right)\right]
\end{aligned}
$$

\section{Policy II under Linear cost Functions C ( $Q$ ) can be derived as:-}

Consider $\mathrm{C}(\mathrm{Q})=\mathrm{C}_{0}-\alpha \mathrm{Q}$, then (22) becomes,

$$
\begin{aligned}
& \mathrm{Z}(\mathrm{Q})= \\
& \mathrm{K}(
\end{aligned}
$$

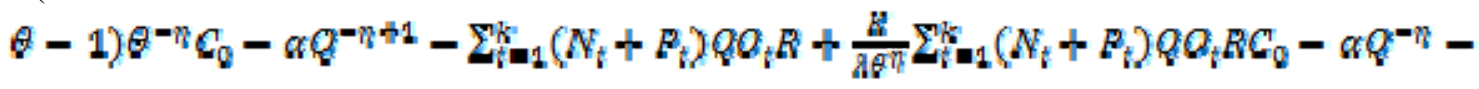

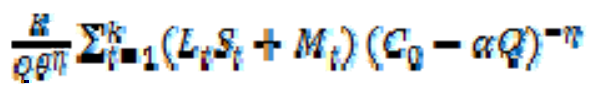

Differentiating equation (23), Finding $\frac{\partial Z}{\partial Q}=0$, we get

$$
\begin{aligned}
& \text { K } \\
& \alpha(\theta-1) \theta^{-n}(\eta-1)\left(C_{0}-\alpha Q^{-\eta}-\sum_{i=1}^{k}\left(N_{i}+E_{i}\right) Q_{i} R+\frac{E_{i}}{d E^{\eta}} \sum_{i=1}^{k}\left(N_{i}+E_{t}\right) Q_{i} R^{2}\left(C_{0}-\right.\right.
\end{aligned}
$$

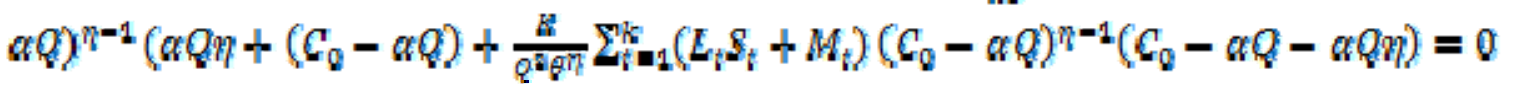

The demand curve becomes a rectangular hyperbola with $\eta \mathbf{1}$ at every point of the curve, hence (33) reduces to,

$$
\begin{gathered}
\sum_{i=1}^{k}\left(N_{i}+P_{t}\right) O_{i} R+\frac{K}{\lambda \theta} \sum_{i=1}^{k}\left(N_{i}+P_{t}\right) O_{i} R+\frac{C_{0}}{\left(C_{0}-\alpha Q^{2}\right)}+\frac{K}{Q^{2} \theta} \sum_{i=1}^{k}\left(L_{i} S_{t}+M_{t}\right) \frac{C_{0}-2 \alpha Q}{C_{0}-\alpha Q^{2}} \\
=0
\end{gathered}
$$

As $\lambda \rightarrow \infty$, equation(34) reduces to, 


$$
Q^{4}-H_{1} Q^{2}+H_{2} Q^{2}+H_{2} Q-H_{4}=q
$$

Where,

$$
\mathrm{H}_{1}=\frac{2 \varsigma_{0}}{x}
$$

$$
\mathrm{H}_{2}=\frac{\mathbb{q}^{2}}{\alpha^{2}}
$$

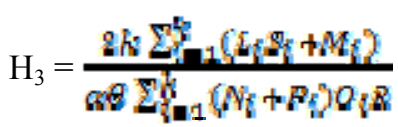

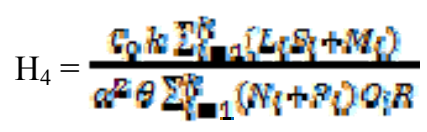

Considering rate of production to be finite, equation (34) becomes,

$$
Q^{4}-H_{8} Q^{8}+H_{6} Q^{2}+H_{8} Q-H_{9}=0
$$

Where

$$
\begin{aligned}
& \mathrm{H}_{5}=\frac{2 \varphi_{0}}{\alpha} \\
& \mathrm{H}_{6}=\frac{\Phi_{0}}{\alpha}-\frac{k}{\alpha \lambda \theta}
\end{aligned}
$$

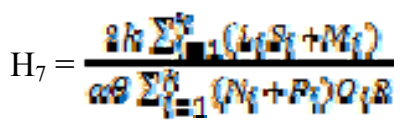

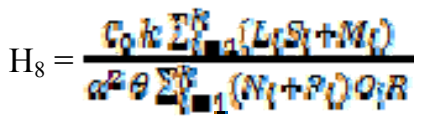

Note:- We can derive the value of $Z^{*}$ at unit elasticity of demand by find $Q=Q^{*}$ from equation (36) and substituting in equation (32).

\section{$\underline{\text { Special Cases }}$}

(a) consider $\eta=1$ in the case of constant cost we get

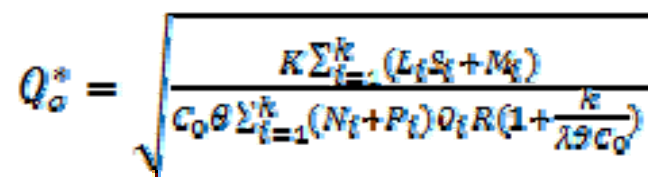

Now if we 
$Z_{c}^{*}=\frac{K \theta-1}{\theta} \sum_{i=1}^{k} N i+P_{i} Q_{c}{ }^{*} O_{i} R+\frac{K}{\lambda \theta C_{0}} \sum_{i=1}^{k} N i+P_{i} Q_{c}^{*} O_{i} R-\frac{K}{\theta C_{0}} \sum_{i=1}^{k} \frac{L_{i} S_{i}+M_{i}}{Q_{c}{ }^{*}}$

(b)

then (38) reduces to,

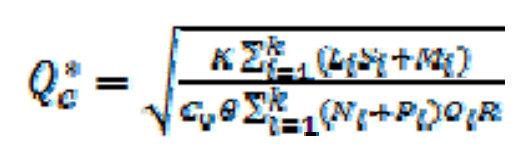

\section{Case (b) : Hyperbolic cost Function :}

For variable cost

$$
\text { ie } \quad C Q=b+\frac{d}{Q}\left(Q_{0} \leq Q<\infty\right)
$$

The profit function becomes,

$$
\begin{aligned}
& \Rightarrow \quad Z Q=K(\theta-1) Q^{-\eta}\left(b+\frac{d}{\theta}\right)^{-\eta+1}-\sum_{i=1}^{k} N_{i}+P_{i} Q O_{i} R+\frac{K}{\lambda Q^{\eta}} \sum_{i=1}^{k} N_{i}+P_{i} Q O_{i} R\left(b+\frac{d}{Q}\right)^{-\eta} \\
& -\frac{K}{\eta} \sum_{i=1}^{k} \frac{L_{i} S_{i}+M_{i}}{Q}+\frac{d^{-\eta}}{Q} \\
& \Rightarrow \quad \frac{\partial Z}{\partial Q}=0 \text { gives } \\
& \Rightarrow \quad \frac{1}{Q^{2}} k(\theta-1) \theta^{-\eta}(\eta-1)+\frac{d^{-\eta}}{Q} \\
& +\sum_{i=1}^{k}\left(N_{i}+P_{i} O_{i} R\right)+\frac{k}{\lambda \theta^{\eta}} \sum_{i=1}^{k}\left(N_{i}+P_{i} O_{i} R\right)+\left(b+\frac{d}{Q}\right)^{-\eta-1} \\
& \left(b+\frac{d}{Q}+\frac{d \eta}{Q}\right) \\
& +\frac{K}{\theta^{\eta} Q^{2}} \sum_{i=1}^{k}\left(L_{i} S_{i}+M_{i}\right)\left(b+\frac{d}{Q}\right)^{-\eta-1}\left(b+\frac{d}{Q}-\frac{d \eta}{Q}\right)=0
\end{aligned}
$$

For special case $\eta=1$ eqn (41) becomes, 


$$
\begin{aligned}
& -\sum_{i=1}^{k} N_{i}+P_{i} O_{i} R+\frac{K}{\lambda \theta} \sum_{i=1}^{k} N_{i}+P_{i} O_{i} R+\left(b+\frac{d}{Q}\right)^{-2}\left(b+\frac{2 d}{Q}\right)+\frac{k b}{\theta Q^{2}} \\
& \sum_{i=1}^{k}\left(L_{i} S_{i}+M_{i}\right)\left(b+\frac{d}{Q}\right)^{-2}=0
\end{aligned}
$$

Simplifying further we get

$$
\begin{aligned}
& \sum_{i=1}^{k} N_{i}+P_{i} O_{i} R+\left(1-\frac{k}{\lambda \theta}\right)\left(b+\frac{d}{Q}\right)^{-2}\left(b+\frac{2 d}{Q}\right)+\frac{k b}{Q \theta^{2}} \\
& \sum_{i=1}^{k}\left(L_{i} S_{i}+M_{i}\right)\left(b+\frac{d}{Q}\right)^{-2} \\
& \Rightarrow \quad Q^{*}=\left[\frac{K b \sum_{i=1}^{k} L_{i} S_{i}+M_{i}}{\theta \sum_{i=1}^{k} N_{i}+P_{i} O_{i} R\left(b+\frac{d}{Q}\right)^{2}-\frac{K}{\lambda \theta}\left(b+\frac{2 d}{Q}\right)}\right]^{1 / 2}
\end{aligned}
$$

Substitutes (42) in (40), to get $Z^{*}$ corresponding to $Q^{*}$

\section{Case of Constant Cost :}

In $C Q=b+\frac{d}{Q}$, assume $d=0 \Rightarrow C Q=b=$ constant; $\left(Q_{0} \leq 1<\infty\right)$

Hence for $\eta=1 \&$ constant cost, we get

$$
Q_{c}^{*}=\left[\frac{K b \sum_{i=1}^{k} L_{i} S_{i}+M_{l}}{\theta \sum_{i=1}^{k} N_{i}+P_{i} Q_{l} R\left(b^{2}-\frac{K b}{\lambda \theta}\right)}\right]^{1 / 2}
$$

And

$$
\begin{aligned}
& Z_{c}^{*}=\frac{K(\theta-1)}{\theta} \sum_{i=1}^{k}\left(N_{i}+P_{i} Q_{c}^{*} O_{i} R\right) \\
& +\frac{K}{\lambda \theta b} \sum_{i=1}^{k}\left(N_{i}+P_{i} Q_{c}^{*} O_{i} R\right)-\frac{K}{\theta b} \frac{\sum_{i=1}^{k}\left(L_{i} S_{i}+M_{i}\right)}{Q_{c}^{*}}
\end{aligned}
$$


If $\lambda \rightarrow \infty$, then $(42) \&(43)$ becomes,

$$
Q^{*}=\left[\frac{K b \sum_{i=1}^{k} L_{i} S_{i}+M_{i}}{\theta \sum_{i=1}^{k} N_{i}+P_{i} O_{i} R\left(b+\frac{d}{Q}\right)^{2}}\right]^{1 / 2}
$$

And

$$
Q_{c}^{*}=\left[\frac{K \sum_{i=1}^{k} L_{i} S_{i}+M_{i}}{\theta \sum_{i=1}^{k} N_{i}+P_{i} O_{i} R b}\right]^{1 / 2}
$$

The above derived cases can be explained further with the help of a numerical problem and conclusion is drawn using total \& partial sensitivity analysis. 